\title{
Initiation and propagation of cleared channels in neutron-irradiated pure copper and a
} precipitation hardened CuCrZr alloy

Singh, B.N; Edwards, D.J.; Bilde-Sørensen, Jørgen

Publication date:

2004

Document Version

Publisher's PDF, also known as Version of record

Link back to DTU Orbit

Citation $(A P A)$ :

Singh, B. N., Edwards, D. J., \& Bilde-Sørensen, J. (2004). Initiation and propagation of cleared channels in neutron-irradiated pure copper and a precipitation hardened CuCrZr alloy. Risø National Laboratory. Denmark. Forskningscenter Risoe. Risoe-R No. 1485(EN)

\section{General rights}

Copyright and moral rights for the publications made accessible in the public portal are retained by the authors and/or other copyright owners and it is a condition of accessing publications that users recognise and abide by the legal requirements associated with these rights.

- Users may download and print one copy of any publication from the public portal for the purpose of private study or research.

- You may not further distribute the material or use it for any profit-making activity or commercial gain

- You may freely distribute the URL identifying the publication in the public portal 


\section{Initiation and Propagation of Cleared Channels in Neutron- Irradiated Pure Copper and aPrecipitation Hardened CuCrZr Alloy}

B.N. Singh, D.J. Edwards and J.B. Bilde-Sørensen 
Author: B.N. Singh, D.J. Edwards and J.B. Bilde-Sørensen Title: Initiation and Propagation of Cleared Channels in Neutron- Irradiated Pure Copper and aPrecipitation Hardened $\mathrm{CuCrZr}$ Alloy

Department: Materials Research Department

Abstract (max. 2000 char.):

The phenomenon of plastic flow localization in the form of "cleared" channels has been frequently observed in neutron irradiated metals and alloys for more than 40 years. So far, however, no experimental evidence as to how and where these channels are initiated during postirradiation deformation has emerged. Recently we have studied the problem of initiation and propagation of cleared channels during post-irradiation tensile tests of pure copper and a copper alloy irradiated with fission neutrons. Tensile specimens of pure copper and a precipitation hardened copper alloy $(\mathrm{CuCrZr})$ were neutron irradiated at 323 and $373 \mathrm{~K}$ to displacement doses in the range of 0.01 to $0.3 \mathrm{dpa}$ (displacement per atom) and tensile tested at the irradiation temperature. The stress-strain curves clearly indicated the occurrence of a yield drop. The post-deformation microstructural examinations revealed that the channels are formed already in the elastic regime and their density increases with increasing plastic strain. The channels appear to have been initiated at grain boundaries, twin boundaries, at relatively large inclusions and even at the previously formed cleared channels. Even though the channels are produced throughout the whole tensile test, no clear evidence has been found for the operation of Frank-Read sources in the volume between the channels. Channels have been observed to penetrate through annealing twins, in some cases stopping at the opposite twin boundary and in other cases penetrating even through the opposite twin boundary and continuing further into the grain. In some cases channels have been found to penetrate through grain boundaries too. It is suggested that the high stress levels reached during deformation of the irradiated specimens activate dislocation sources at the sites of stress concentration at the boundaries and inclusions. The propagation of these newly generated dislocations in the matrix causes the formation of cleared channels. Implications of these results are discussed with specific reference to the origin and consequences of plastic flow localization.
Risø-R-1485(EN)

October 2004

ISSN 0106-2840

ISBN 87-550-3385-7 (Internet)

Contract no.:

Group's own reg. no.:

(Føniks PSP-element)

Sponsorship:

Cover :

Pages: 29

Tables/figures: 10

References:

Risø National Laboratory

Information Service Department

P.O.Box 49

DK-4000 Roskilde

Denmark

Telephone +4546774004

bibl@risoe.dk

Fax +45 46774013

www.risoe.dk 


\section{Contents}

\section{Abstract}

\section{Introduction 5}

2. Materials and Experimental Procedure 6

\section{3. $\quad$ Results 7}

3.1 Microstructure and tensile behaviour in the as-irradiated state 7

3.2 Post-Irradiation deformation microstructure 8

\section{Discussion 11}

4.1 Dislocation sources and a sudden yield drop $\mathbf{1 1}$

4.2 Initiation and propagation of cleared channels $\mathbf{1 2}$

4.3 Transmission of cleared channels 14

4.4 Plastic flow localization in the cleared channels and mechanical performance

5. Summary and Conclusions 16

\section{Acknowledgement 17}

\section{References 17}




\section{Introduction}

It is well established from post-irradiation mechanical testing that neutron irradiation at temperatures below recovery stage $\mathrm{V}$ (i.e. $<0.4 \mathrm{~T}_{\mathrm{m}}$ for fcc copper where $\mathrm{T}_{\mathrm{m}}$ is the melting temperature) causes substantial hardening and a severe reduction in the ductility of metals and alloys. The characteristics of radiation hardening are more complicated than the simple increase in strength and loss of ductility, however. The increase in yield strength often includes the occurrence of a sudden yield drop, a decrease in the ability of the irradiated material to deform homogeneously and a severe loss of work hardening ability. This behaviour has been demonstrated by an overwhelming amount of indisputable experimental evidence obtained from post-irradiation mechanical testing and microstructural characterization of irradiated FCC, BCC and HCP metals and alloys (see Singh et al. 1997 for a review). These dramatic changes in mechanical behaviour pose a matter of serious concern from the point of view of performance and lifetime of materials used in the structural components of fission or fusion reactors.

One of the most significant microstructural features emerging from post-irradiation investigations is the observation of "cleared" channels, narrow bands of material ( $\sim 50$ $200 \mathrm{~nm}$ in width) often completely cleared of the defects produced during irradiation by the successive passage of dislocations generated from some dislocation source within the material. In the more extreme cases of localized plastic deformation, the plastic strain is confined almost entirely to these narrow channels. The post-deformation microstructure of irradiated materials exhibiting a prominent yield drop clearly demonstrates that the plastic deformation is initiated in a very localized fashion and confined almost exclusively to the "cleared" channels (see Luft 1991 and Victoria et al. 2000 for a review). The observation of these channels was first reported by Greenfield and Wilsdorf (1961). Since then a number of investigations have reported the formation of cleared channels in post-irradiated and deformed metals and alloys, but to our knowledge no definitive and conclusive experimental evidence exists in the literature demonstrating the sites where these channels are actually initiated during post-irradiation tensile tests of neutron-irradiated bulk specimens of metals and alloys. It should be mentioned here that recently Robach et al. (2003) have presented some results of post-irradiation, in-situ straining experiments on ion-irradiated thin foils of copper. These results are taken to be the direct evidence for the initiation of a cleared channel from a grain boundary. It is worth pointing out, however, that the presence of surfaces and the wedge-shaped configuration of the thin foils used in these experiments introduce a number of uncertainties in the interpretation of the observations made during in-situ straining experiments. Consequently, it would only be prudent to exercise caution when considering these results to be "definitive and conclusive" evidence for the initiation of a cleared channel at a grain boundary. It is also very important to point out that very little is known about the relationship between the phenomena of yield drop and of cleared channel formation, the two most important phenomena commonly observed during postirradiation deformation experiments. As to when these channels are initiated and how they evolve as deformation continues also remain to be established.

Recently, we have investigated some of the issues mentioned above and intend to communicate the salient features of our results in the present paper. Materials and experimental procedure are described in section 2. In section 3 , we first present the microstructure and tensile behaviour of pure copper and $\mathrm{CuCrZr}$ alloy in the as-irradiated condition (section 3.1). We then report the main results of post-irradiation deformation experiments (section 3.2) illustrating the sites where channels are initiated. Results demonstrating propagation of channels and their interaction with other features of the microstructure are also presented in this section. Implications and significance of these results are discussed in section 4. Finally, a summary and main conclusions are given in section 5 . 


\section{Materials and Experimental Procedure}

The following provides a brief description of the materials and experimental procedures used in the present experiments to provide the framework for experimental characterization described in this paper. For additional details the reader is referred to the appropriate reference. Two materials were used in the present investigation. The first was thin $(0.3 \mathrm{~mm})$ sheet of oxygen-free high conductivity (OFHC) copper containing 10 , $<3,<1$ and $<1 \mathrm{ppm}$ respectively of $\mathrm{Ag}, \mathrm{Si}, \mathrm{Fe}$ and $\mathrm{Mg}$. The oxygen content of this copper was found to be $34 \mathrm{appm}$. Similar sheets of the alloy $\mathrm{CuCrZr}(\mathrm{Cu}-0.8 \% \mathrm{Cr}, 0.07 \% \mathrm{Zr}$, $0.01 \% \mathrm{Si}$ ) were also used. Prior to irradiation, both materials were given separate heat treatments. The OFHC copper samples were annealed at $823 \mathrm{~K}$ for 2 hours in a vacuum of $\sim 10^{-6}$ torr. The resulting grain size and dislocation density were $30 \mu \mathrm{m}$ and $\leq 10^{12} \mathrm{~m}^{-2}$, respectively.

The $\mathrm{CuCrZr}$ was given a prime ageing heat treatment consisting of solution annealing at $1223 \mathrm{~K}$ for $1 \mathrm{~h}$, water quenching, then ageing at $748 \mathrm{~K}$ for $30 \mathrm{~min}$. and water quenching. The grain size and dislocation densities were similar to that of the OFHC copper. The ageing treatment produces a fine dispersion of small spherical precipitates ranging from 0.36 to $0.59 \times 10^{23} \mathrm{~m}^{-3}$ in density with an average size of 2.3 to $2.9 \mathrm{~nm}$ (Edwards et al. 2002). The nature of these small precipitates remains unclear, but are thought to be primarily small $\mathrm{Cr}$-rich precipitates with some $\mathrm{Cu}-\mathrm{Zr}$ precipitates present (Singh et al. 1997). A very low density of large Cr-rich inclusions is present in the grain interiors and at grain boundaries.

Two irradiation experiments were conducted wherein tensile samples of the two materials were irradiated in the DR-3 reactor at Risø National Laboratory. All tensile specimens used in the present work were $\sim 0.3 \mathrm{~mm}$ thick and $39 \mathrm{~mm}$ long with a $7 \mathrm{~mm}$ long and $3 \mathrm{~mm}$ wide gage section. The first experiment involved irradiating tensile specimens at $373 \mathrm{~K}$ to different displacement doses in the range of 0.01 to $0.3 \mathrm{dpa}$ (displacements per atom) with a displacement damage rate of $\sim 5 \times 10^{-8} \mathrm{dpa} / \mathrm{sec}$. In the second experiment a set of five tensile samples of OFHC-Cu were irradiated at a slightly lower irradiation temperature of $323 \mathrm{~K}$ to $0.3 \mathrm{dpa}$.

The irradiated specimens of OFHC-Cu and $\mathrm{CuCrZr}$ from the first experiment were tensile tested to failure at $373 \mathrm{~K}$ at a strain rate of $1.2 \times 10^{-3} \mathrm{~s}^{-1}$ in vacuum $\left(\leq 10^{-4}\right.$ torr $)$. Characterization of the microstructures of the as-irradiated and irradiated and deformed samples was performed using a JEOL 2000FX transmission electron microscope (TEM). For the post-deformation microstructural investigations of the samples, thin foils were prepared from $\sim 2 \mathrm{~mm}$ wide strips taken from the portion of the gauge length closest to the fracture surface of the tensile specimens. Specimens were prepared by electropolishing the specimens using a $25 \%$ perchloric acid, $25 \%$ ethanol and $50 \%$ water electrolyte at $295 \mathrm{~K}$ (for $15 \mathrm{sec}$ ), 9.5 volts and $\sim 20 \mathrm{~mA}$.

For the case of the OFHC-Cu samples irradiated at $323 \mathrm{~K}$ in the second experiment, a series of tests were conducted at $295 \mathrm{~K}$ where a given tensile specimen was stopped at a specific tensile strain and the deformed microstructure characterized. One specimen was tested to failure ( $22 \%$ total elongation), one specimen loaded to $\sim 90 \%$ of the upper yield stress, unloaded and then removed from the test fixture, and the remaining 3 specimens strained plastically to $1.5,5$ or $14.5 \%$ elongation, unloaded and then removed from the tensile machine. The gauge surfaces of the tensile samples were examined in a JEOL 840 SEM to document the slip step evolution in each strained condition. The surfaces of the samples were moderately oxidized from the solution annealing treatment and subsequent irradiation, however, distinct slip steps could be observed in enough detail to establish the qualitative characteristics of their distribution across the gauge section. Characterization of the microstructure of the various deformed samples was performed using a JEOL 2010F field emission-gun transmission electron microscope (FEG-TEM) operated in both transmission and scanning transmission mode. By virtue of the amplified contrast obtained from the STEM detector and the high intensity convergent probe, STEM imaging proved particularly useful to observe the deformed microstructure in regions too 
thick for ordinary TEM imaging. All STEM images were taken in bright field. For TEM specimen preparation $3 \mathrm{~mm}$ discs were punched from the center of the gauge length of tensile specimens after the tests were stopped. These discs were twin-jet electropolished at $293 \mathrm{~K}$ in a solution of $25 \%$ phosphoric acid, $25 \%$ ethylene glycol and $50 \%$ water at $\sim 180 \mathrm{~mA}$ and $14 \mathrm{~V}$.

\section{Results}

\subsection{Microstructure and tensile behaviour in the as-irradiated state}

\subsubsection{OFHC-Cu and CuCrZr alloy}

The results of the microstructural characterization for both materials in the asirradiated condition have been reported in detail elsewhere (Singh et al. 2001, Edwards et al. 2002) and will only be briefly summarized here. The as-irradiated OFHC-Cu and CuCrZr specimens contained a high density $\left(\sim 5 \times 10^{23} \mathrm{~m}^{-3}\right)$ of small $(\sim 2.5 \mathrm{~nm})$ stacking fault tetrahedra (SFTs) homogeneously distributed throughout the grains. While the average size of the SFTs $(\sim 2.5 \mathrm{~nm})$ was found to be independent of dose and material, the density increased to a saturation level of $\sim 5 \times 10^{23} \mathrm{~m}^{-3}$ as the dose increased from 0.01 dpa to $0.1 \mathrm{dpa}$. Above $0.1 \mathrm{dpa}$ no further changes were apparent with respect to the SFTs. Examples of the SFTs are shown in figure 1a along with their size distributions as a function of dose (figure 1b).

At the lowest dose of $0.01 \mathrm{dpa}$, small distinct dislocation loops were present in the OFHC-Cu in a much lower density $\left(\sim 5 \times 10^{21} \mathrm{~m}^{-3}\right)$ than that of the SFTs (see figure 1(a) in Singh et al. 2001). Although the character of the loops was not determined in the present study, Singh et al. (2001) considered the loops to be of interstitial type based on their post-irradiation annealing results. This is quite consistent with the well established results of Burger's vector analysis showing unambiguously that the loops formed in neutron-irradiated copper are of interstitial type (e.g. Singh et al. 1986 and English et al. 1987). At doses of $0.1 \mathrm{dpa}$ and greater, the small loops coalesced to form raft-like agglomerates of loops that at first glance appeared as a loose network of dislocation segments (see figures 2a and 3a in Singh et al. 2001). The defect microstructure in the irradiated $\mathrm{CuCrZr}$ alloy at 0.3 dpa was essentially identical to that of the OFHC-Cu. Irradiation at $373 \mathrm{~K}$ coarsened the precipitate microstructure by lowering the density slightly (to $\sim 0.26 \times 10^{23} \mathrm{~m}^{-3}$ ) and significantly increased the average size of the precipitates to $\sim 5.5 \mathrm{~nm}$. No direct evidence was found of precipitation on the loop agglomerates or dislocation lines in the irradiated $\mathrm{CuCrZr}$ alloy. The as-irradiated specimens of OFHC-Cu were further investigated using positron annihilation spectroscopy with the conclusion that these specimens did not contain vacancy agglomerates in the form of voids (Eldrup and Singh 2000).

The formation of a high density of small SFTs and the network-like agglomerations of dislocation loops led to pronounced changes in the tensile behavior of both materials. In the case of the OFHC-Cu, a significant increase (factor of $\sim 5$ ) in strength occurred along with the appearance of a sharply defined yield point beginning at $0.01 \mathrm{dpa}$ (see figure 2a). The changes in yielding behaviour were accompanied by a large reduction in the elongation (both uniform and total) and work hardening ability. At $0.1 \mathrm{dpa}$ and above the OFHC copper exhibited a distinct yield drop followed by a brief plateau in the stressstrain curve resembling a Lüder's plateau. Some work hardening persisted up to $0.3 \mathrm{dpa}$ but was rather minimal compared to that of the unirradiated OFHC-Cu. The upper yield strength at the highest dose was approximately a factor of 9 higher than the $0.2 \%$ offset yield strength of the unirradiated samples. Despite the severe loss of ductility and work hardening ability, the material failed in a ductile manner.

In the case of the $\mathrm{CuCrZr}$ alloy, the increase in yield strength was much higher than in OFHC-Cu, and this was accompanied by a complete loss of uniform elongation and 
work hardening in tension. This is illustrated in figure $2 b$ where the tensile curves for the as-irradiated $\mathrm{CuCrZr}$ are presented. Edwards et al. (2002) proposed that the visible precipitates and SFTs could not be completely responsible for this extra hardening, and suggested that radiation-induced segregation of impurities and alloying elements on dislocations may also contribute to hardening. As a consequence of this increased hardening, the tensile specimens were forced into a plastic instability and began necking upon reaching the yield, or maximum strength in this case. As in the case of the neutronirradiated OHFC-Cu, the failure mode was found to be ductile at both 0.2 and $0.3 \mathrm{dpa}$.

\subsubsection{Interrupted post-irradiation tensile tests}

Although the irradiation temperature was lower compared with the previous experiment on OFHC-Cu (323K vs. 373K), the density and size distribution of the SFTs were essentially the same. Agglomerations of the interstitial loops were present in nearly the same density, so that microstructurally there were only minor differences between the two sets of irradiated samples that could be measured in the TEM. The overall tensile response is shown in figure $2 \mathrm{c}$, with the strains indicated where each of the individual specimens were stopped. The tensile tests were more sensitive to the lower irradiation temperature, which lead to slightly more hardening and loss of elongation and work hardening ability compared with the OFHC-Cu samples irradiated at 373K. The tensile curves shown in figure $2 \mathrm{c}$ confirm that a yield drop is present at this irradiation condition, followed by a small plateau before a minimal degree of work hardening begins. The material retains the ability to substantially neck in tension despite the radiation hardening, which has been observed in all other tests of irradiated copper of which we are aware.

\subsection{Post-Irradiation Deformation Microstructure}

\subsubsection{General Description}

The general features of the post-irradiation deformation microstructure showing the formation of cleared channels in OFHC-Cu and $\mathrm{CuCrZr}$ alloy have been described elsewhere (see Singh et al. 2001, Edwards et al. 2002 and Edwards and Singh 2004) and only the pertinent features will be briefly summarized here. The deformation microstructures were observed in TEM foils taken as close as possible to the failure region.

In the case of OFHC-Cu irradiated to $0.01 \mathrm{dpa}$ and irradiated and tested at $373 \mathrm{~K}$, deformation occurred via a mixture of dislocation channeling along the [111] planes and homogenous dislocation activity. At doses of 0.1 dpa and higher, the OFHC-Cu deformed almost exclusively via dislocation channeling on the [111] slip planes. In the case of the $\mathrm{CuCrZr}$ samples irradiated to 0.2 and $0.3 \mathrm{dpa}$, qualitatively there was little to distinguish the channel characteristics (e.g. width and size) from those observed in OFHC-Cu except in one notable regard. Whereas the channels in the OFHC-Cu were generally free of defects and dislocation debris, the dislocation channels in $\mathrm{CuCrZr}$ contained varying degrees of dislocation debris as well as the small precipitates.

Examples of the channels in the two materials are shown in figure 3, with the rough boundaries of the channels highlighted by the dashed marks. Because of their small size, it could not be determined with confidence whether the small precipitates inside the channels in the $\mathrm{CuCrZr}$ had been altered by the passage of the dislocations. The channel spacing and density varied from grain to grain in both materials, but in all cases the grains near the final failure region contained some dislocation channels. Generally, the edges of the dislocation channels in both OFHC-Cu and $\mathrm{CuCrZr}$ were clean in the sense that no debris from the dislocation/defect interactions were swept to the side of the channels, suggesting that the defects were annihilated completely and absorbed by the mobile dislocations.

At doses of 0.1 dpa and higher, a small degree of local dislocation movement was observed outside the channels. However, this arose primarily because the rafts of loops 
and dislocation segments that formed during irradiation appeared to interact with each other, leading to a higher fraction of dislocation segments that then moved slightly under the applied strain. The movement of these dislocation was fairly limited since they were quickly and effectively pinned by the surrounding defects. Work hardening remained minimal under these conditions as only a local rearrangement of existing dislocations occurred. In contrast to the OFHC-Cu, no significant dislocation generation or movement occurred outside the channels in the $\mathrm{CuCrZr}$ even at the very high stresses created during the tensile test, presumably due to additional segregation of impurities and alloying elements and/or radiation-induced precipitation on the dislocations.

In the interrupted stress-strain tests, the slip step evolution was characterized from very low strains up to the point of failure. The sample tested to failure exhibited significant ability to reduce in area, eventually necking down to a narrow "knife-edge" fracture surface with ductile dimples in the final, separated region. The surface of the specimens were slightly oxidized, but the SEM revealed that the slip steps were still visible through this thin oxide layer. The images illustrated that a substantial grain-tograin variability in the surface density of slip steps persisted up to the point of failure. Figure 4 provides examples of the slip step evolution as a function of strain. Very few slip steps were observed in the sample stopped before the yield point, but in the samples tested to higher strains the number of grains with visible slip steps increased. The images show the slip steps to be coarse and planar in nature with very little slip occurring inbetween the slip steps. The nature of the slip steps was the same even in the necked region, leading the authors to conclude that the same deformation processes continued to operate during necking. It appeared that the average spacing of slip steps decreased as well, however, since different samples were used at each level of strain, the development of the slip steps in a particular area could not be followed. Not only did the number of slip steps increase globally within the gauge section, but additional slip systems appeared to be operating in grains that had considerably more slip activity than adjacent grains.

Examination by TEM of the samples strained to different strain levels revealed narrow dislocation channels (50-200 nm in width) that appeared to increase in spatial frequency as the plastic strain increased. A very rough comparison of the spacing between parallel dislocation channels observed in the TEM was found to match qualitatively the slip step spacing observed in the SEM images, however, the grain-tograin variability observed in the TEM foils precludes a precise comparison. In the sample stopped at the ultimate tensile stress and in the sample tested to failure, most grains exhibited a high degree of channeling, in agreement with the SEM observations.

Examples of the dislocation channels at the various levels of deformation are shown in figures 5 . In the sample stopped just before yield, very few channels could be found in the TEM foil, and the foil itself showed no bending or other evidence of strain inside the foil despite being subjected to $\sim 270 \mathrm{MPa}$. In figures $5 \mathrm{a}$ and $5 \mathrm{~b}$, three channels are shown within the same grain, all of which impinge upon or originate from the same grain boundary. Note that the diffuse channel shown in figure $5 \mathrm{~b}$ still contains a significant fraction of the defects plus additional dislocations that have been moving through the still forming channel. The rafts of dislocation loops and dislocation segments outside the channels appeared unaffected at this stage of the tensile test. At higher strains, the rafts of loops and dislocation segments interacted under the applied stress as described earlier in the section on the post-irradiation deformation tests to failure.

Most channels spanned the width of the grain and stopped only at grain boundaries, however in limited cases the interfaces of annealing twins also provided one endpoint for channels. Several cases were observed of dislocation channels cutting through annealing twins and continuing until the channel reached a grain boundary where it stopped (more will be mentioned about annealing twins in a later section). The channels in thin regions of the foil rarely contained more than isolated dislocations, and dislocation tangles were only observed when two operating channels intersected each other or a channel intersected some interface such as a twin or a grain boundary. Finally, no accumulation of dislocations occurred within the channels that would promote any work hardening, that 
is, no cell walls or forest hardening type interactions appear to have formed within the channels.

\subsubsection{Channel Initiation and Propagation}

In the following, we present results and analysis of investigations showing for the first time direct evidence for the initiation of cleared channels from interfaces such as annealing twins and inclusions in neutron-irradiated OFHC-Cu and $\mathrm{CuCrZr}$ alloy. A definitive example of channel initiation from an interface in OFHC-Cu irradiated to 0.3 dpa at $373 \mathrm{~K}$ and subsequently tensile tested at $373 \mathrm{~K}$ is shown in figure $6(\mathrm{a}-\mathrm{c})$. The annealing twin reveals closely-spaced dislocation channels initiated from one interface of a twin boundary, propagating through the twinned volume on the [111] planes and ending at the opposite twin boundary. It is of particular interest to notice that the cleared channels inside the annealing twin (figure 6a) are quite regularly spaced and are of similar width. The tensile axis is parallel to the twin interface, leading to a shear stress along the interface. Note that there is evidence of considerable plastic shear at the interfaces where the channels have impinged upon the twin boundary. The bright field and dark field TEM images shown in figure $6 \mathrm{~b}$ and $6 \mathrm{c}$ highlight the concentrated strain fields where the channels impinged upon the twin boundary. These images were taken from a different region of the same annealing twin shown in figure 6a. The diffraction pattern (see insert in figure 6b) taken from the regions of stress concentrations provide the evidence for lattice rotation caused by the accumulation of dislocations where the channels impinge upon the twin boundaries. Note that the actual initiation point of the channels cannot be pinpointed based on these images as the point of origin may be outside the TEM foil.

As suggested earlier in the introduction, grain boundaries are also thought to act as a primary source of channels, but unfortunately only indirect evidence exists to support this hypothesis. With rare exception, channels have only been observed to run completely across grains from one boundary to another. Examples of channels interacting with grain boundaries are shown in figure 7. In figure 7a the STEM image from the OFHC-Cu tensile sample stopped at $1.5 \%$ strain shows the impingement of a channel in the upper grain on a grain boundary. The channel locally sheared the grain boundary, producing a heavily strained region with dislocation pileups and what appeared to be a low angle boundary on each side of the channel near the boundary. The TEM image in figure $7 \mathrm{~b}$ is from the same area and better illustrates the dislocation walls that have formed along the outer edges of the channel in the upper grain. The channel continues into the next grain from the intersection point (see figure $7 \mathrm{c}$ also), but this channel is not as well developed as the preceding channel. Note that the grain boundary in both figures has a defect free zone (DFZ) along the grain boundary in the lower grain. While no grain boundary channel sources have been positively identified that were activated independently by the applied macroscopic stress, both the SEM and TEM indicated the impingement of channels on a grain boundary could initiate new channels in the adjacent grain. Conversely, there are many cases where a particular grain has numerous channels crossing the width of the grain, but there is no relationship with channels in the neighboring grains that can be readily understood.

Another type of interface at which channels initiated was the large inclusions observed in the $\mathrm{CuCrZr}$ alloy, where very large inclusions $(0.5-1 \mu \mathrm{m}$ diameter) present from the initial heat treatment act as sites for stress concentrations. Figure 8 shows a channel emanating from a hole in the TEM foil that formed where a large inclusion etched out during electropolishing. Similar examples have been reported in the $\mathrm{CuCrZr}$ alloy tested after irradiation under low cycle fatigue (Singh et al. 2000). The $\mathrm{CuCrZr}$ alloy possesses a relatively large number of these inclusions, whereas the $\mathrm{OFHC}-\mathrm{Cu}$ is essentially free of any such sources of stress concentrations.

Channel initiation also occurs as a result of the intersection of individual channels, which yields complex dislocation interactions that can lead to the formation of another channel. However, it has also been observed that intersecting channels on different slip 
systems do not always interact at their point of intersection, instead, one of the channels is simply sheared by the other channel. This indicates that the two channels formed at different stages of deformation and that the later generation of channel sheared the preexisting channel. The lack of any dislocation tangles or interactions may imply that the channel sheared by the second generation channel was no longer operative. Very often channels have also been found to initiate at a pre-existing channel which ends at another pre-existing channel parallel to the first one. The image shown in figure 9 provides an example of these narrow connecting channels, and in fact show that they are three different generations of channels present. The different generations of channels are labeled as (a), (b) and (c). These very narrow channels (c) appear to have started from the edges of the larger, primary channels, but no dislocation activity is found at the end of these channels to indicate what type of interactions produced this phenomenon.

One final detail worth pointing out is how effective dislocation channels are at transmitting slip. In figures $5 \mathrm{c}$ and 10 , three examples are shown of annealing twins that have been cut by one or more dislocation channels. In each case the dislocation channel(s) have completely crossed across the annealing twin and shearing it by a $100 \mathrm{~nm}$ or more at each point. The dislocation interactions at the interface cannot be ascertained, but there are clearly dislocations piled up at the interface on the each side, as well as in the channeled volume inside the twin itself. The annealing twin in figure 10a dramatically illustrates the tremendous shear that can occur as a result of interaction between dislocation channels and an annealing twin. In this case numerous dislocation channels have moved through the annealing twin, leaving behind a heavily sheared and damaged twin with varying shear and rotation at each point of intersection. This clearly illustrates that not only are the channels capable of causing a tremendous amount of local damage when they interact with a boundary, but also complex slip interactions occur when the dislocations interact with interfaces. In the case of a grain boundary, such heavily damaged regions may act as crack nucleation sites (see section 4.3 for further discussion).

\section{Discussion}

Experimental observations presented in the previous section illustrate the following important features:

(a) the occurrence of a sudden yield drop,

(b) the initiation of cleared channels at the regions of stress/strain concentrations,

(c) localization of plastic flow exclusively in the cleared channels,

(d) a lack of global dislocation generation in the grain interior (i.e. the volume between the cleared channels)

Since these features are closely linked, it is relevant to establish the physical basis and the main processes responsible for giving rise to these features. This, in our view, would be of a great help in identifying the role of each of these features in determining the mechanical response of irradiated materials during post-irradiation tests.

\subsection{Dislocation sources sand a sudden yield drop}

It is well known that the occurrence of a sudden and prominent yield drop requires (a) that the density of mobile dislocations is very low (e.g. when most of the grown-in dislocations are locked) and (b) that at a certain stress level (i.e. the upper yield stress) the rate of dislocation multiplication becomes very high (i.e. a large number of dislocations are suddenly unlocked or generated from sources) (Hahn 1962). The resulting strain rate in the specimen exceeds the applied strain rate causing a drop in the load acting on the specimen. The phenomenon of yield drop is commonly observed in unirradiated bcc 
metals (e.g. Seidel 1969) and alloys and is known to occur as a result of unlocking of dislocations from the "atmosphere" of carbon and nitrogen atoms (Cottrell and Bilby 1949). The occurrence of yield drop has been observed even in the unirradiated fcc copper containing small amounts of zinc (Ardley and Cottrell 1953). In this case the atmosphere of zinc atoms causes the locking of the grown-in dislocations. It should be emphasized here that the yield drop in the unirradiated metals and alloys occurs due to unlocking of the grown-in dislocations in the grain interiors throughout the whole specimen.

In the case of the irradiated materials, the occurrence of the yield drop during postirradiation tensile testing has been treated in terms of the cascade induced source hardening (CISH) model (Singh et al. 1997, Trinkaus et al. 1997). According to the CISH model, the yield drop would occur if a large number of decorated dislocations in the grain interiors were suddenly released from their decoration and were to act as F-R sources. The resolved shear stress necessary for unlocking the decorated dislocations in the copper irradiated and tested at $323 \mathrm{~K}$ was estimated to be $300 \mathrm{MPa}$ (Singh et al. 1997). This is considerably higher than the resolved shear stresses corresponding to the measured tensile stresses at the upper yield point in our experiments (see figures $2 a$ and $2 b$ ). In other words, the resolved shear stress experienced by the decorated dislocations in our experiments is not high enough to unlock them. This is consistent with the experimental observations during post-irradiation tensile deformation, where practically no dislocations are generated in the grain interiors (i.e. the decorated dislocations remain locked). In spite of this, a well defined yield drop is observed. This leads to the unavoidable conclusion that the dislocations necessary for producing the yield drop must have been generated at some other sites than the decorated dislocations in the grain interiors. As suggested earlier by Singh $(1998,1999)$ and Ghoniem et al. (2001), these sites of dislocation sources must be the regions of stress /strain concentrations (e.g. boundaries, interfaces, surfaces etc.) in the material. This hypothesis is confirmed by the evidence presented in the previous section. In summary, during deformation of irradiated materials, the yield drop is caused by the initiation of a sufficiently large number of dislocation sources at the regions of stress/strain concentrations (e.g. at grain boundaries and twin boundaries) and not by the unlocking of the decorated grown-in dislocations in the grain interiors.

Although there is, to our knowledge, no evidence available at present showing the generation of dislocations at grain or twin-boundaries in irradiated metals and alloys, a good number of such results have been published for unirradiated metals. Recently, Sutton and Baluffi (1995) have reviewed the literature on dislocation generation from general grain boundaries as well as from special boundaries such as $\Sigma 3$ [111] twin boundaries. It was proposed, for example, already in 1957 by Whelan et al. (1957) that Frank-Read sources inside a $\Sigma 3$ [111] twin boundary were responsible for the lattice dislocations they observed emanating from the twin boundary. Murr (1975) and Kurzydlowski et al. (1984) have shown that dislocations can be emitted from general grain boundaries, including even those boundaries that initially contained no dislocations within the boundary itself. Recently, Konopka et al. (2000) and Nørbygaard and BildeSørensen (2001) have presented the evidence for dislocation generation from twin boundaries in an austenitic stainless steel and $\mathrm{Cu}-2 \% \mathrm{Ni}$ alloy, respectively.

\subsection{Initiation and propagation of cleared channels}

Once the new, and "clean" (i.e. undecorated) dislocations are generated at these sites of high stresses, their natural high velocity (see Osetsky et al. 2004) allows them to propagate rapidly on the glide planes containing relatively soft obstacles. The resulting interactions between the fast moving dislocations and the soft obstacles on the glide planes cause the complete destruction and removal of the obstacles produced during irradiation. This was found to be true even in the precipitation hardened $\mathrm{CuCrZr}$ alloy irradiated to 0.2 and $0.3 \mathrm{dpa}$ at $373 \mathrm{~K}$, where the precipitate size and density apparently were not sufficient to prevent the dislocations from removing the irradiation-induced 
defect clusters on the glide planes and forming the cleared channels (Edwards et al 2002). Thus, it is the combination of the decoration pinning of the grown-in dislocations (preventing them from acting as F-R sources) and the existence of soft obstacles (small SFT, dislocation loops and small, weak precipitates) that lead to the flow localization in the form of cleared channels. Note that an intermediate situation can exist at low enough doses, where deformation may initially occur by channel formation, but as the stress and strain increases some of the weakly pinned F-R sources in the grain interiors may get unlocked. In this case, a mixture of dislocation channels and homogenous plastic flow may be observed in the microstructure. An example of this very situation was reported by Singh et al. (2001) in the case of post-irradiated annealed and tested OFHC-Cu and later for post-irradiated annealed and tested CuCrZr alloy (Edwards et al. 2002).

With respect to channel initiation from a boundary, a definitive example of this for the case of OFHC-Cu is provided in figure 6 , where distinct, periodic channels were initiated inside an annealing twin in neutron irradiated and tensile tested OFHC-Cu. A possible explanation of this regularity and the inability of the channels to move outside the annealing twin boundaries is that the channels are initiated at ledges on the twin boundaries. If the misorientation across a coherent twin boundary does not deviate from the exact CSL orientation by more than a few degrees, then the misorientation from the exact $\{111\} /\{111\}$ boundary plane can be accommodated by the introduction of ledges on the $\{1177\} /\{1355\}$ (Huang 2002). This is in accordance with the calculated boundary energy as a function of the boundary orientation for the $<011>$ tilt twin boundary. Two minima are found, one for the coherent twin, the other for a boundary inclined at $82^{\circ}$ with respect to the coherent twin boundary (Wolf et al. 1992). Since the ledges are introduced to compensate for a deviation from the exact $\{111\} /\{111\}$ boundary orientation, it would be expected that they are spaced rather regularly. This may not be the only possible explanation, but the regular spacing can hardly be explained unless the channels are initiated at the boundaries.

The propagation of dislocation channels through the twin boundaries shown in figures $10 \mathrm{a}$ and $10 \mathrm{~b}$ illustrates that a considerable amount of shear is produced in the dislocation channels. Further, the transfer of shear across the twin boundary, through the twin and into adjacent matrix indicated that the interfaces do not necessarily present effective obstacles to slip transmission. The analysis of such boundary interactions with channels may reveal that dislocations from the impinging channel may be partially transmitted through and partially incorporated into the twin interface, much as described by Lee at al., 1990 (see also Sutton and Balluffi, 1995, pp. 733) for stainless steel. In that case they observed that the impingement of lattice dislocations on a $\Sigma 3$ twin boundary produced both new lattice and grain boundary dislocations, the latter of which glided along the twin boundary away from the site of the intersection. The grain boundary dislocations were stopped further along the twin interface at a step in the twin boundary, providing a stress concentration that separately emitted lattice dislocations into the adjacent grain. The lattice dislocations formed directly from the dislocation pile-up at the $\Sigma 3$ twin boundary, on the other hand, moved away from the twin boundary into the adjacent lattice. For the twin boundary shown in figure 10b, it is not clear if only lattice dislocations from the channel were directly transmitted through the boundary, if some component of the dislocations was incorporated into the twin interface, or if the pile-up of dislocations at the interface produced a high enough stress concentration to form a matching channel on the other side of the interface.

There is a wide variability in the channel width observed experimentally in regions outside of the annealing twins, examples of which are illustrated in figures 9. Here, there are at least two, if not three different generations of visible cleared channels that appear to have formed at different stages during the deformation. Clearly, the first generation of channels is wider than the last generation of channels, which are merely connecting the adjacent primary channels, but for some reason, do not extend past these channels to the other parallel channels. At present, there exists no clear explanation for how the narrower connecting channels have formed nor what determines the final width of the channels. Assuming the mechanism of climb-controlled glide of dislocations in the channels, 
Ghoniem et al. (2001) have suggested that the width of the channels may be determined by the size of the obstacles on the glide plane and the distance between the F-R sources and the boundary. However, so far this suggestion has not been validated by experiments. Recently Hiratani et al. (2002) have suggested that the stress-induced transformation of SFT into Frank sessile loops (FSL) combined with the double cross slop of screw dislocations (Diaz del la Rubia et al. 2000) may control the width of cleared channels. However, the hypothesis of the collapse of SFTs into FSLs has not been confirmed experimentally either. Thus, at present, there seems to be no clear, complete and reliable explanation for the large variability in the width of cleared channels observed experimentally.

\subsection{Transmission of cleared channels}

As shown in section 3, once initiated at sources, the high velocity of the dislocations at the front of the channel makes the front of the cleared channel propagate very rapidly through the grain interior until it meets an obstacle such as a grain or a twin boundary, a large inclusion or even another operating cleared channel on a different slip system. Clearly, some of them do manage to propagate through grain boundaries or twin boundaries and enter the grain interior on the other side of the grain or twin boundaries. In many other cases, however, they are not transmitted into the other grain and remain contained between two grain boundaries or twin boundaries. These observations are, in general terms, consistent with the conclusion of Shen et al. (1988) that events such as dislocation transmission across a grain boundary take place at a variety of local stresses and encounter a wide range of obstacle strengths. In a recent atomistic computer simulation study of dislocation transmission through grain boundaries, Christiansen et al. (2004) have shown that such interactions very often produce sessile dislocation configuration instead of transmission.

In view of the lack of detailed crystallographic information on the results presented in section 3, it is not possible to discuss the mechanisms of either the initiation of cleared channels or their transmission across grain boundaries or twin boundaries. However, it is relevant to consider the consequences of interactions between cleared channels and boundaries or surfaces. In cases when the channels are stopped at a boundary (e.g. figure 6), all the dislocations propagating within the channels are deposited at the boundary where the channels end. As a result, a substantial amount of strain accumulates in a localized fashion at the boundary. The accumulated strain at the boundary, is, as shown in figures $6 \mathrm{~b}$ and $6 \mathrm{c}$, high enough to cause even local lattice rotation. In cases where the channels get transmitted across the boundary, they cause a heavy shear damage to the boundary (figures 7 and 10) localized at the site of interaction between the channel and the boundary.

\subsection{Plastic flow localization in the cleared channels and mechanical performance}

Finally, let us examine the role of plastic flow localization in the cleared channels in determining the mechanical performance (the occurrence of yield drop, a drastic decrease in the ability of material to work harden and almost a complete loss of ductility). Before considering this relationship let us note the following features of the channel formation demonstrated by the experimental results reported in section 3: (i) cleared channels are formed even before the yield drop, (ii) in the samples irradiated to 0.3 dpa the formation of new channels continues with increasing plastic strain, yet practically no F-R sources become operative in the volume between the channels, (iii) cleared channels were observed in specimens irradiated to only $0.01 \mathrm{dpa}$ where no yield drop was observed and (iv) channels were also observed in specimens irradiated to $0.3 \mathrm{dpa}$ and then annealed at $573 \mathrm{~K}$ for $50 \mathrm{~h}$ and tested at $373 \mathrm{~K}$. In the latter case the tensile response showed that 
post-irradiation annealing completely removed the yield point and restored a significant level of work hardening ability (Singh et al. 2001), however, the overall elongation levels remained much lower than their unirradiated counterpart.

A physically realistic interpretation of the observations listed in items (i), (iii) and (iv) is that under these conditions, only a few dislocation sources at interfaces become operative, thereby forming such a limited number of cleared channels that the total rate of dislocation generation from these sources is not enough to exceed the externally applied strain rate. Hence, the tensile tests do not exhibit a yield drop. Following the discussion in section 4.1, in order to produce a prominent yield drop during a tensile test, the number of channels (and thereby the number of mobile dislocations) operating at a certain stress level must be high enough to induce a strain rate which is clearly higher than the applied strain rate. This assertion is perfectly valid and is supported by the experimental fact that practically no dislocations are generated in the volumes between the channels in specimens exhibiting a prominent yield drop (item ii) and that the work hardening is very limited beyond the yield point.

Thus, in the context of radiation hardening by small defect clusters, the occurrence of a yield drop during a post-irradiation tensile test shows that a large number of cleared channels are formed already at the upper yield stress. This means that as the test continues, practically all plastic deformation gets localized in the cleared channels and remain localized even at higher strain levels (see item (ii)). The degree of channeling versus uniform deformation, which is dose dependent, will likely control the overall level of uniform elongation at intermediate doses. This is supported by the fact that even in the post-irradiation annealed samples where annealing removed the yield drop and restored work hardening, the overall elongation compared to the unirradiated condition remained low most probably because of channel formation.

As discussed in section 4.3, the interaction of these channels with grain boundaries may produce a significant amount of "damage" (strain) accumulation localized at the sites of channel-boundary interaction. This kind of strain accumulation may cause nucleation of cracks at the grain boundaries (Luft 1991, Dai and Victoria 1997) and may be responsible for the drastic reduction in the uniform elongation of materials irradiated and tested at temperatures below the recovery stage V. In summary, it is the nature and magnitude of the localized grain boundary damage caused by the impingements of the cleared channels which is likely to determine the ductility (uniform elongation) of materials irradiated and tested at temperatures below $0.3-0.4 \mathrm{~T}_{\mathrm{m}}$.

It should be pointed out that according to the arguments presented in this section, the formation of cleared channels and the occurrence of yield drop could be avoided by preventing the long range transport of dislocations generated at dislocation sources at grain boundaries and interfaces. This can, at least in principle, be achieved by additions of closely-spaced strong (i.e. Orowan-type) obstacles (e.g. oxide particles) to metals and alloys prior to irradiation. Although this possibility has not been investigated systematically, there are at least a limited number of experimental results which show that a fine dispersion of yttrium oxide $\left(\mathrm{Y}_{2} \mathrm{O}_{3}\right)$ in zirconium alloy $(\mathrm{Zr}-2)$ (Singh et al. 1973) and aluminium oxide $\left(\mathrm{Al}_{2} \mathrm{O}_{3}\right)$ particles in copper (Singh et al. 1996) prevents the phenomena of yield drop and plastic instability. In the case of $\mathrm{Zr}-2$, the addition of 10 vol.\% of $\mathrm{Y}_{2} \mathrm{O}_{3}$ made it possible for the irradiated alloy even to work harden. It should be added that the presence of a high density $\left(\sim 10^{24} \mathrm{~m}^{-3}\right)$ of precipitates $\sim 4 \mathrm{~nm}$ in size in a precipitation hardened CuNiBe alloy (Singh et al. 1996) prevents the yield drop and the onset of plastic instability.

Finally, it is worth emphasizing that the results and their implications presented and discussed in this paper refer exclusively to post-irradiation deformation experiments. A different situation may arise under realistic reactor conditions where the material is likely to be exposed simultaneously to both irradiation and plastic strain, thus substantially altering the interaction and the accumulation of defects. It is quite likely, therefore, that under in-reactor test conditions the material may behave very differently, a problem that is being investigated by carrying out in-reactor tensile tests (Singh et al. 2003, 2004). 


\section{Summary and Conclusions}

Experimental results have firmly established that the plastic deformation of materials irradiated and tested in the post-irradiation condition at temperatures below the recovery stage $\mathrm{V}$ (i.e. $<0.4 \mathrm{~T}_{\mathrm{m}}$ for fcc copper) is dominated by the phenomena of yield drop, lack of work hardening, and cleared channel formation. Experiments have also revealed another interesting feature that the formation of cleared channels occurs even before the yield point (i.e. the upper yield stress) and that the phenomenon continues throughout the whole tensile test period. Significantly enough, during the whole test period practically no dislocations are produced outside the channels in the grain interiors.

It has been argued that since the stress necessary to activate the decorated dislocations as F-R sources in the grain interiors is very high, the dislocation sources are activated at the sites of stress/strain concentrations (e.g. boundaries, interfaces, etc.) in a localized fashion. It should be noted that because of the stress intensification, the local stress acting at these sources must be considerably higher than the nominal global stress indicated by the tensile machine. Once the sources are activated, the freshly generated "clean" dislocations move at high velocity on the appropriate glide plane and remove the irradiation-induced "soft" obstacles present on the glide plane. Thus, the dislocation sources at boundaries and interfaces are the sources of cleared channels.

Once the number of these channels generated becomes large enough to induce a strain rate in the specimens which is greater than the applied strain rate the yield drop occurs. Thus, it follows that if the soft obstacles on the glide planes were replaced by a dense population of hard and insurmountable obstacles, the dislocations generated at these sources would not be able to move through the channels and the resulting pile-up of dislocations and the back stress would stop the sources. This would prevent both the formation of cleared channels and the occurrence of yield drop. Experimental results confirm this conclusion.

Once formed, the cleared channels propagate very rapidly in the grain interior until they intercept an obstacle such as a boundary, an interface or even another cleared channel. Evidence has been presented to show that in some cases channels are stopped at these obstacles and in other cases they are transmitted across them. In both cases, the boundaries and interfaces are locally damaged by shear displacements and/or stress/strain concentrations. This occurs because most of the dislocations generated at the sources are transported through the channels and are deposited at the sites where the channels end. In case of grain boundaries, such sites may become potential crack nucleation sites. Although limited in number, some experimental results do exist to support this conclusion.

Finally, we may conclude that although the phenomenon of the yield drop and channel formation are interconnected, it is the interaction of these channels with grain boundaries that causes the grain boundary damage and may be the main reason for the reduction in the uniform elongation in materials irradiated and tested at temperatures below the recovery stage V. It is also reasonable to conclude that the origin of the channel formation lies in the decoration of grownin dislocations with defect clusters (and impurities) so that they cannot be activated as F-R dislocation sources in the grain interiors. Consequently, dislocation sources (i.e. sources of cleared channels) are activated at the regions of stress/strain concentrations (e.g. boundaries and interfaces). It must be recognized, however, that the exact mechanism of channel initiation and their subsequent evolution as a function of strain still remains unknown. 


\section{Acknowledgement}

The present work was partly funded by the European Fusion Technology

Programme. DJ Edwards would like to thank Risø National Laboratory for the support and assistance during his visits. This work was partly supported by the U.S. Department of Energy under Contract DE-AC06-76RLO 1830 with the Battelle Memorial Institute at the Pacific Northwest National Laboratory. The authors would like to thank Dr. Helmut Trinkaus for valuable comments and suggestions.

\section{References}

ARDLEY, G.W., and COTTRELL, A.H., 1953, Proc. R. Soc. A219, 328.

CHRISTIANSEN, J., SCHIØTZ, J., JACOBSEN, K.W., LEFFERS, T., and BILDESØRENSEN, J.B., 2004, to be published.

COTTRELL, A.H., and BILBY, B.A., 1949, Phys. Soc. London, 62A, 49.

DAI, Y., and VICTORIA, M., 1997, in: Microstructure Evolution During Irradiation, eds. I.M. Robertson et al., MRS Symposium Proceedings, 439, Materials Research Society, Pittsburgh, 1997, 319.

DIAZ DE LA RUBIA, T., ZBIB, H.M., KHRAISHI, T.A., WIRTH, B.D., VICTORIA, M., and CATURLA, M.J., 2000, Nature, 406, 871.

EDWARDS, D.J., and SINGH, B.N., 2004, J. Nucl. Mater., 329-333, $1072 .$.

EDWARDS, D.J., SINGH, B.N., XU, Q., and TOFT, P., 2002, J. Nucl. Mater., 307 311, 439.

ELDRUP, M., and SINGH, B.N., 2000, J. Nucl. Mater., 276, 269.

ENGLISH, C.A., EYRE, B.L., and MUNCIE, J.M., 1987, Phil. Mag. A56, 453.

GHONIEM, N.M., TONG, S.-H., SINGH, B.N., and SUN, L.Z., 2001, Phil. Mag. A81, 2743.

GREENFIELD, G.I., and WILSDORF, H.G.F., 1961, J. Appl. Phys., 32, 827.

HAHN, G.T., 1962, Acta Metall., 10, 727.

HIRATANI, M., ZBIB, H.M., and WIRTH, B.D., 2002, Phil. Mag., 82, 2709.

HOWE, L.M., 1974, Radiat. Eff., 23, 181.

HUANG, X., 2002, Mater. Sci. Forum, 408-412, 493.

KONOPKA, K., MIZERA, J., and WYRZYKOWSKI, J.W., 2000, J. Mater. Process. Techn., 99, 255.

KURZYDLOWSKI, K.J., VARIN, R.A., and ZIELINSKI, W., 1984, Acta Met., 32, 71.

LEE, T. C., ROBERTSON, I. M., and BIRNBAUM, H. K., 1990, Met. Trans., 21A, 2437.

LUFT, A, 1991, Prog. Mater. Sci., 35, 97.

MURR, L.E., 1975, Metall. Trans., 6A, 505.

NØRBYGAARD, T., and BILDE-SØRENSEN, J.B., 2001, Proc. of the 9th Conf. on Creep-Fracture of Engineering Materials and Structures, Swansee, 1 - 4 April, 2001, Ed. J.D. Parker, Inst. of Materials., London, 15.

OSETSKY, Y.N., BACON, D.J, RONG, Z., and SINGH, B.N., 2004, Phil. Mag. Letters, in press.

ROBACH, J.S., ROBERTSON, I.M., WIRTH, B.D., and ARSENLIS, A., 2003, Phil. Mag., 83, 955.

SEIDEL, G.P., 1969, Radiat. Eff., 1, 177.

SHEN, Z., WAGONER, R.H., and CLARK, A.T., 1988, Acta Metall., 36, 3231.

SINGH, B.N., LEFFERS, T., and HORSEWELL, A.H., 1986, Phil. Mag., A53, 233.

SINGH, B.N., 1998, J. Nucl. Mater., 258- 263, 18; 1999, J. Computer-Aided Mater. Desn., 6, 195.

SINGH, B.N., EDWARDS, D.J., and TOFT, P., 1996, J. Nucl. Mater., 238, 244.

SINGH, B.N., EDWARDS, D.J., ELDRUP, M. and TOFT, P., 1997, J. Nucl. Mater., 249, 1.

SINGH, B.N., EDWARDS, D.J., and TOFT, P., 2001, J. Nucl. Mater., 299, 205. 
SINGH, B.N., FOREMAN, A.J.E., and TRINKAUS, H., 1997, J. Nucl. Mater., 249, 103.

SINGH, B.N., STUBBINS, J.F., and TOFT, P., 2000, Risø Report no. Risø-1128(EN), Risø National Laboratory.

SINGH, B.N., WARREN, M.R., and PARSONS, P.D., 1973, in: Nuclear Fuel Performance, Proc. Int. Conf. London, 15 - 19 Oct. 1973, British Nuclear Energy Soc., eds. C.T. John, B. Wyles and B. Moore (BNES, 1973), paper no. 64.

SINGH, B.N., TÄHTINEN, S., MOILANEN, P., JACQUET, P., and DEKEYSER, J., 2003, J. Nucl. Mater., 320, 299.

SINGH, B.N., EDWARDS, D.J., TÄHTINEN, S., MOILANEN, P., JACQUET, P., and DEKEYSER, J., 2004, Phil Mag., to be submitted.

SUTTON, A.P., and BALUFFI, R.W., 1995, Interfaces in Crystalline Materials (Oxford: Clarendon Press). 730-744

TRINKAUS, H., SINGH, B.N., and FOREMAN, A.J.E., 1997a, J. Nucl. Mater., 249, 91; 1997b, ibid., 251, 172.

VICTORIA, M., BALUC, N., BAILAT, C., DAI, Y., LUPPO, M.I., SCHÄUBLIN, R., and SINGH, B.N., 2000, J. Nucl. Mater., 276, 114.

WHELAN, M.J., HIRSCH, P.B., HORNE, R.W., and BOLLMANN, W., 1957, Proc. Roy. Soc., A240, 524.

WOLF, U., ERNST, F., MUSCHIK, T., FINNIS, M., and FISCHMEISTER, H.F., 1992, Phil. Mag., A66, 991. 


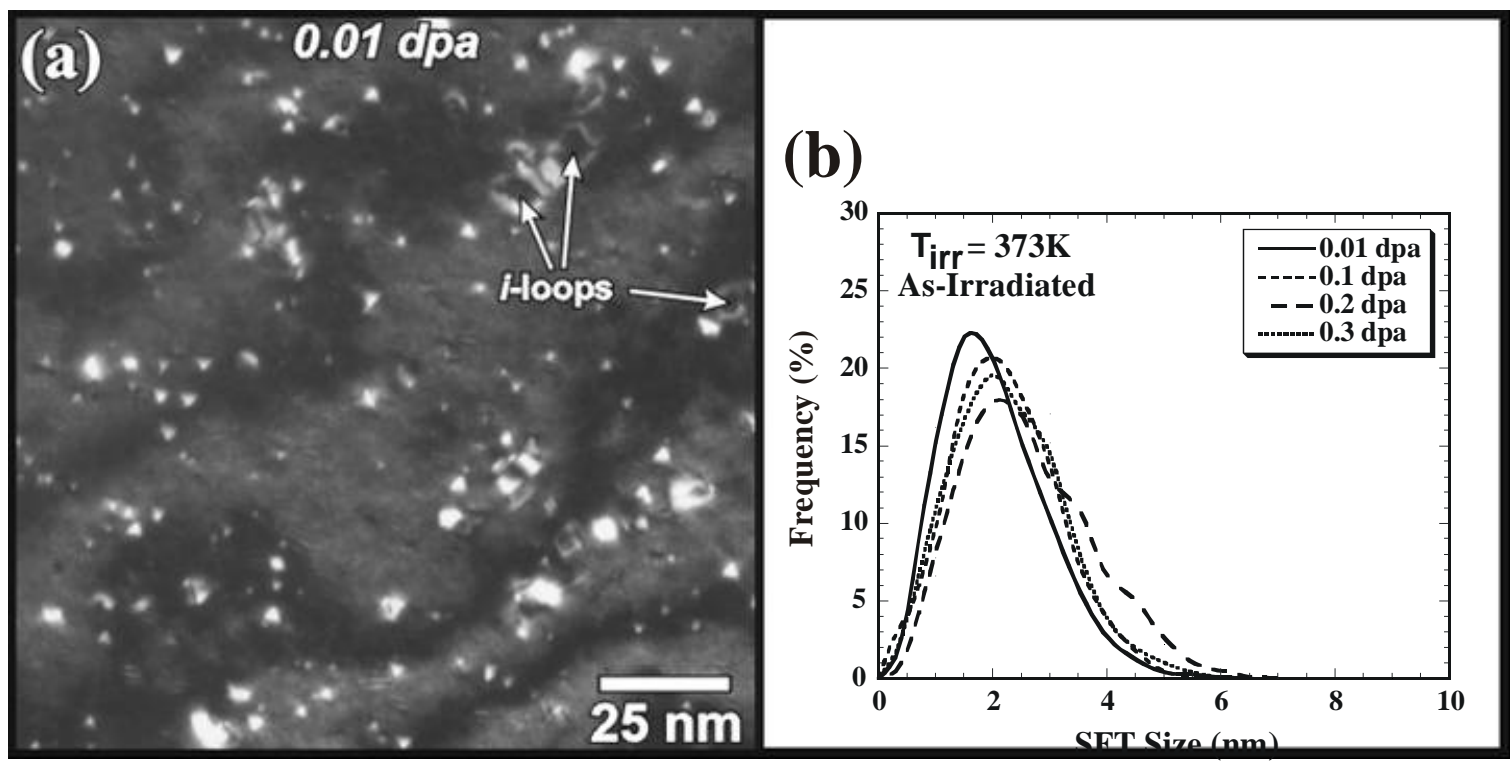

Figure 1. Stacking fault tetrahedra (SFT) and interstitial loops in OFHC-Cu irradiated at $373 \mathrm{~K}$ are shown in (a), along with the size distributions of the SFT as a function of dose in (b). The image in (a) was taken near an $<011>$ zone axis in a weak beam dark field condition using $(\mathrm{g},+5 \mathrm{~g}) \mathrm{g} 200$ condition near the same zone axis. 

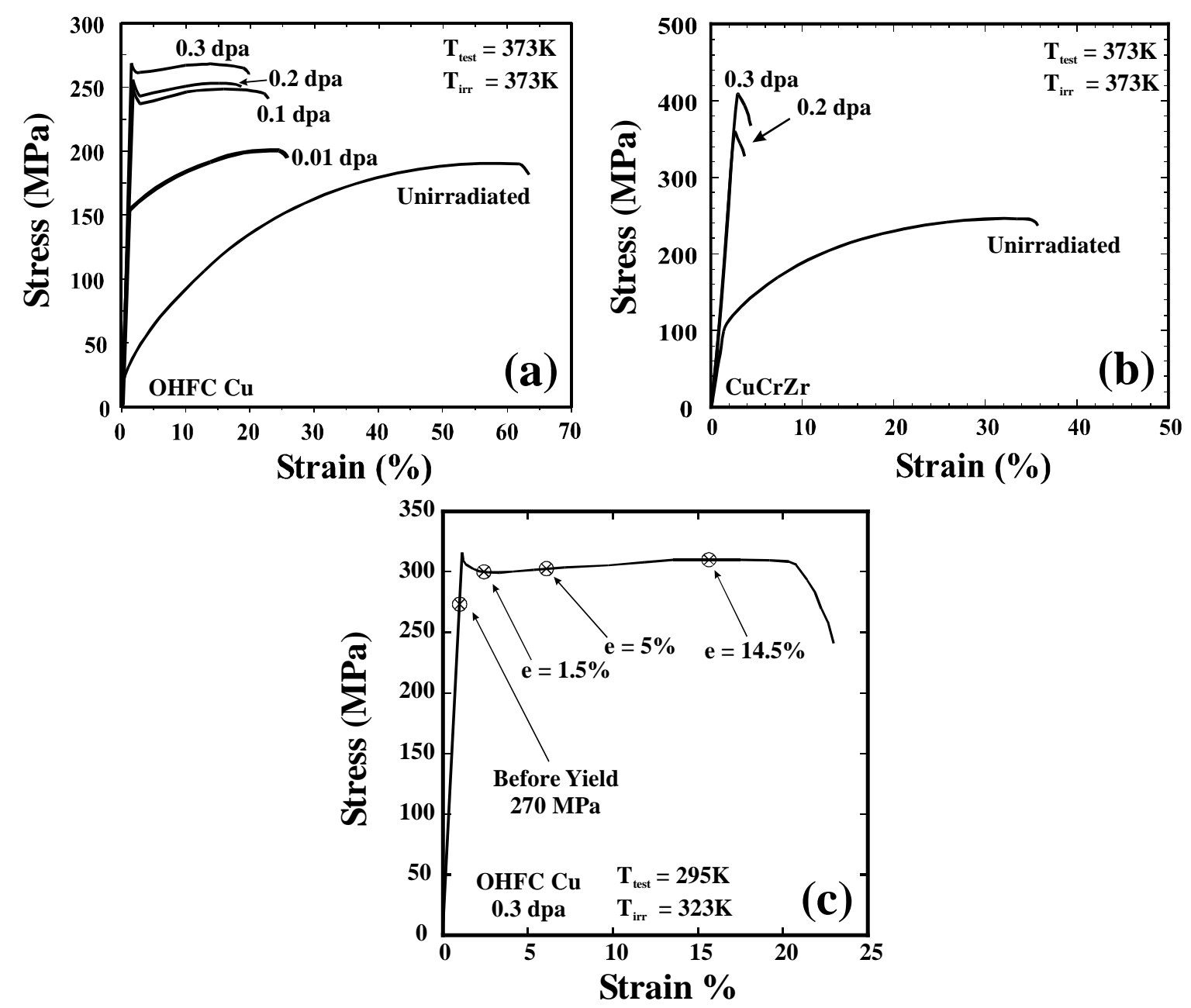

Figure 2. Tensile curves for (a) OFHC-Cu and (b) $\mathrm{CuCrZr}$ demonstrate the dramatic changes in mechanical properties that occur due to irradiation below recovery stage V. The tensile curve in (c) illustrates the various stress and strains at which tensile tests on individual samples of OFHC-Cu irradiated to $0.3 \mathrm{dpa}$ were stopped in order to examine the microstructure at a particular stress and strain level. 


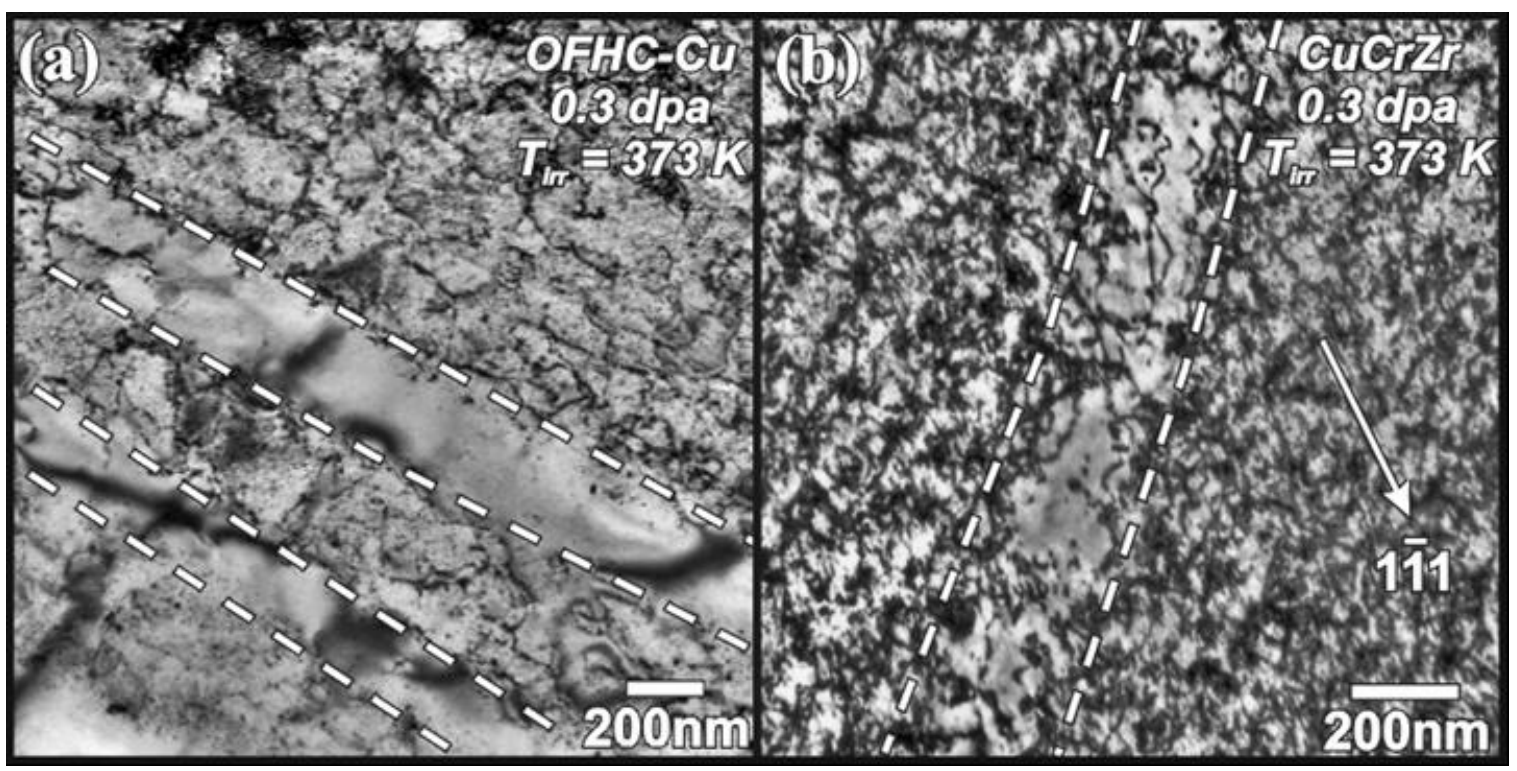

Figure 3. The image in (a) shows that deformation in OFHC-Cu occurred primarily through cleared channels with limited dislocation activity outside the channels. The example of dislocation channels (b) from irradiated $\mathrm{CuCrZr}$ indicate that the channels are not as free of dislocations or defects as those of the OFHC-Cu at comparable doses. 


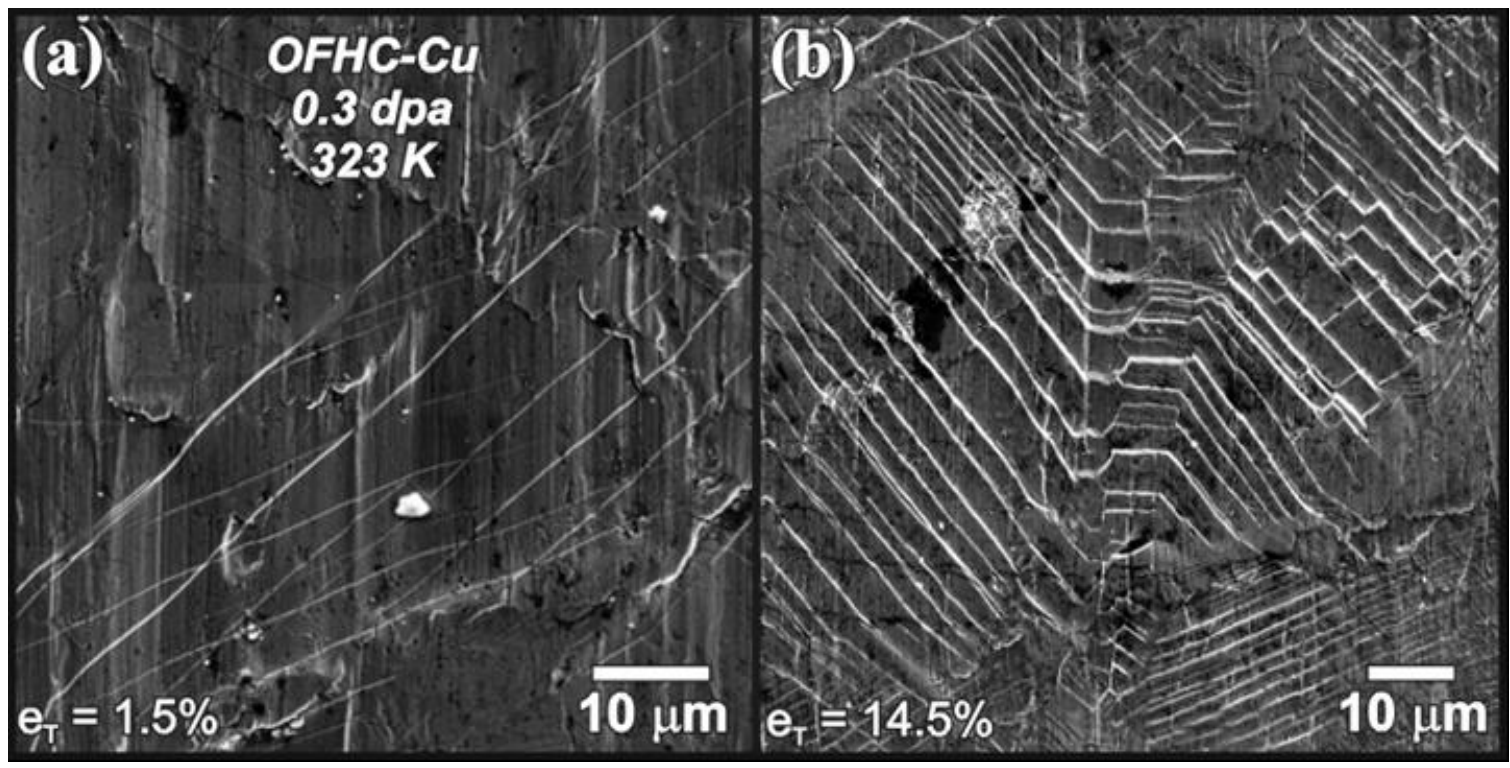

Figure 4. This figure illustrates the evolution of the slip steps that intersect the gauge surface of the OFHC-Cu tensile specimens $\left(T_{\text {irr }}=323 \mathrm{~K}, 0.3 \mathrm{dpa}, \mathrm{T}_{\text {test }}=295 \mathrm{~K}\right)$ stopped at the indicated strain. Note that the number of slip steps increases with increasing strain. 


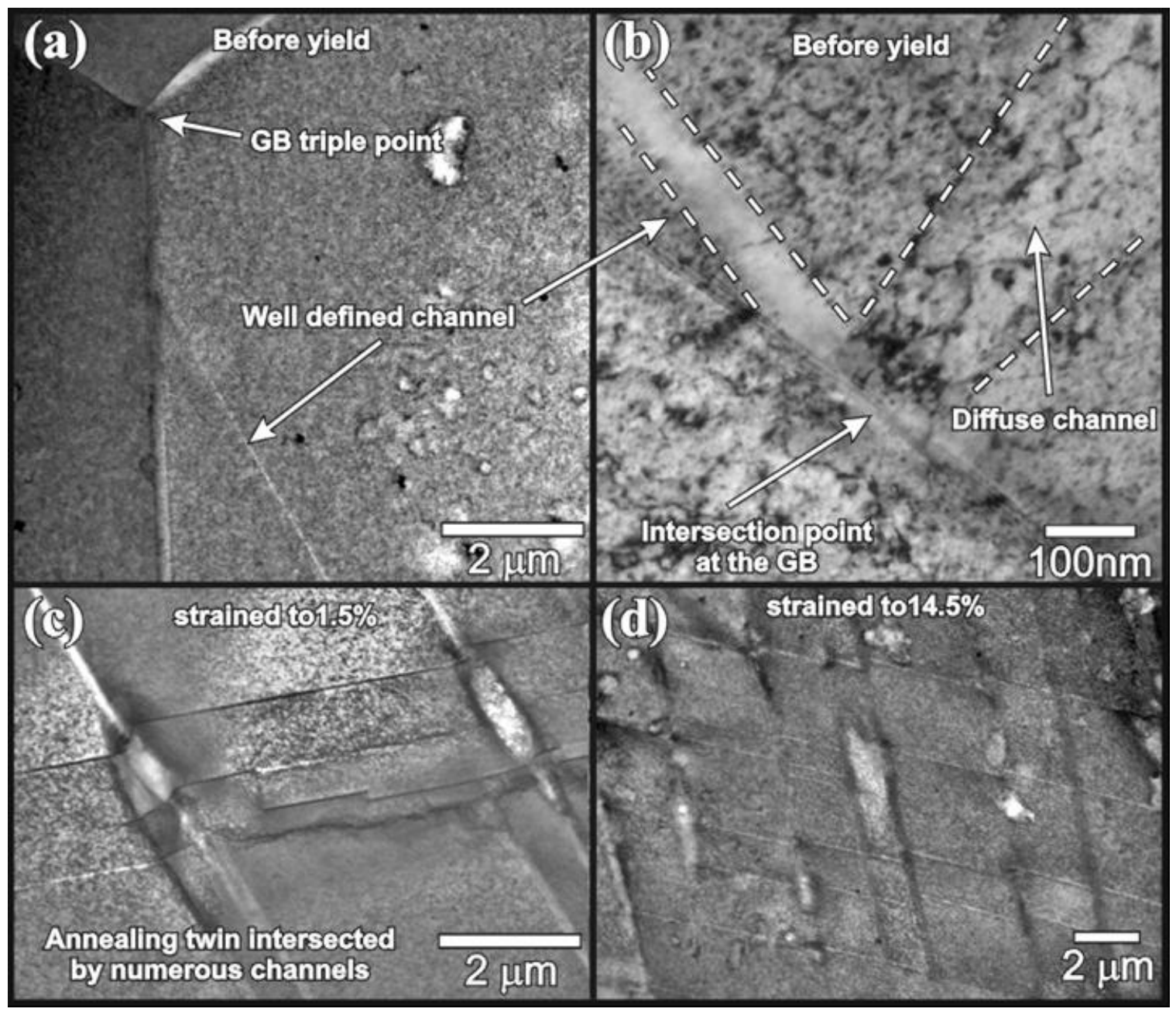

Figure 5. In the OFHC-Cu irradiated at $323 \mathrm{~K}$ to 0.3 dpa and tensile tested at $323 \mathrm{~K}$, only a few channels could be found in the sample stopped before yield, examples of which are shown in (a) and (b). The image shown in (c) shows an annealing twin being intersected by two dislocations channels, as well as having a channel initiated inside the annealing twin from a ledge. Near the ultimate tensile strength $(\varepsilon=14.5 \%)$, the grain shown in (d) is subdivided by numerous channels formed on different slip planes. All four images were taken in the STEM bright field mode. 


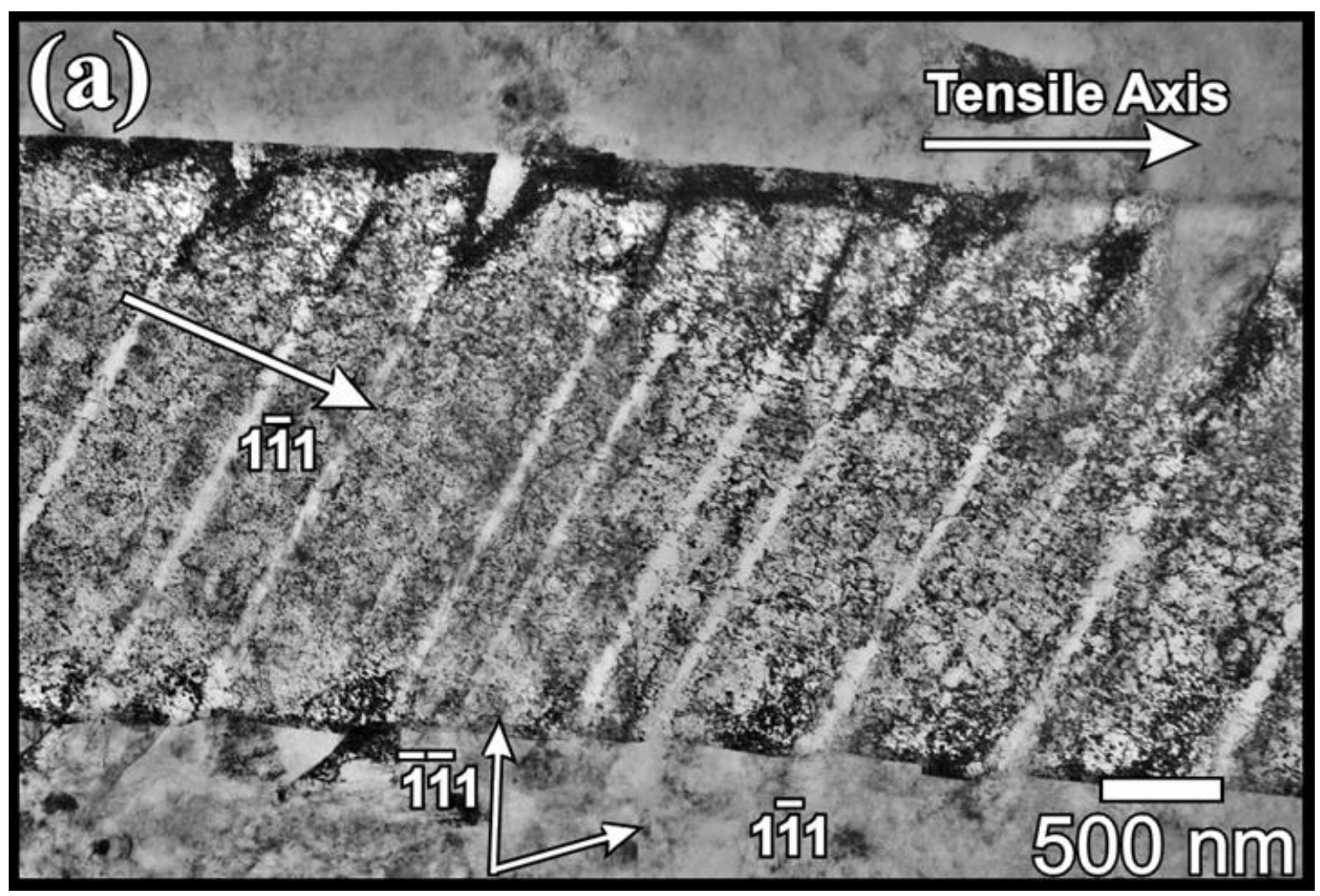

Figure 6. Cleared channels inside an annealing twin in OFHC-Cu irradiated and tested at 373K. Images shown in (b) and (c) were taken from a different region of the same annealing twin shown in (a). Channel initiation was found to occur inside the annealing twin at different points along the interface, presumably from ledges in the twin boundaries (see text for explanation). The channels were unable to exit the twin at either interface, resulting in strain accumulation on both the inside (b) of the annealing twin where the channels intersected, and (c) on the outside of the annealing twin. Note that the diffraction pattern taken from the regions of strain concentration shows that the strain accumulation is large enough to cause local lattice rotation. 

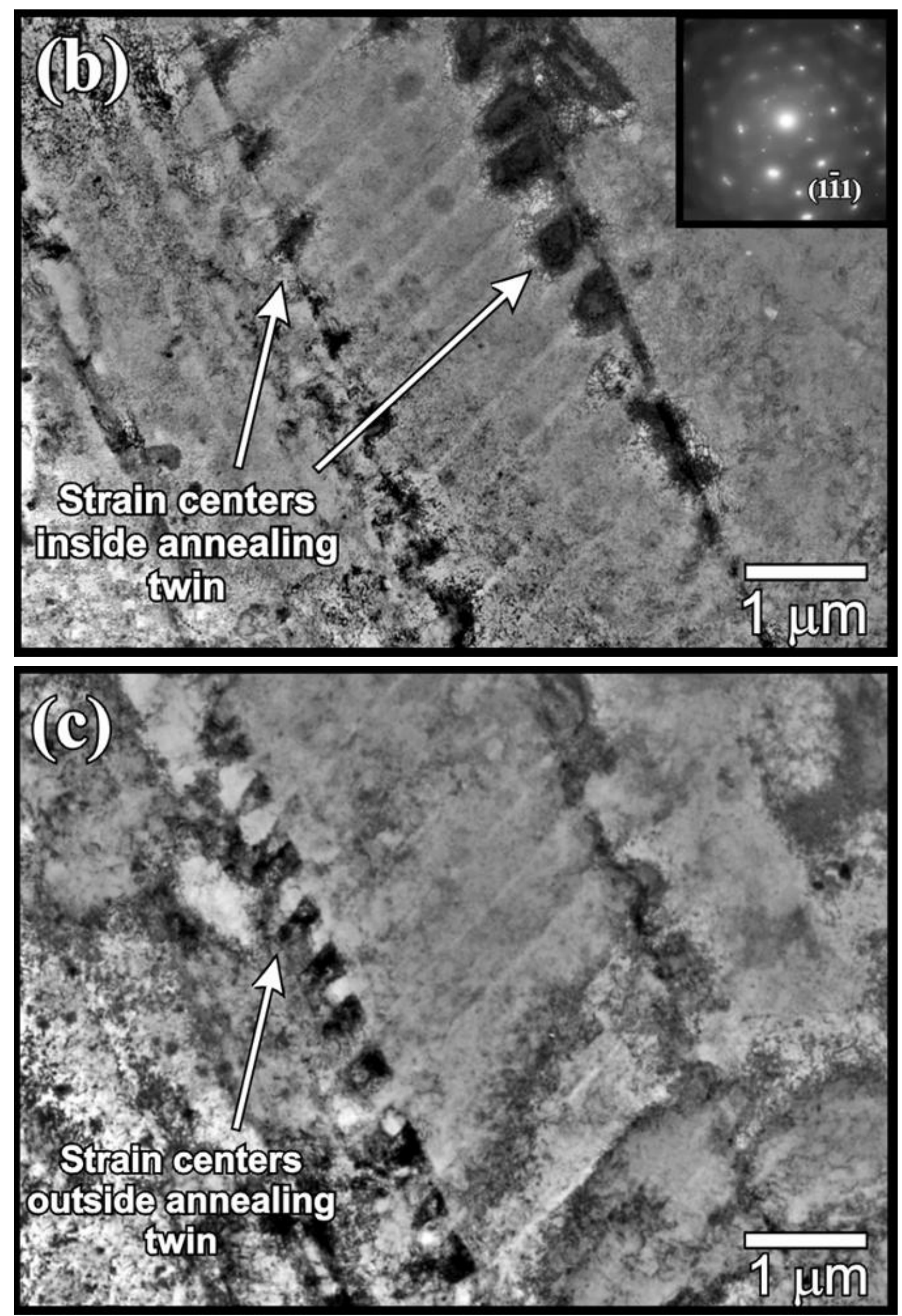

Figure $6 \mathrm{~b} \& \mathrm{c}$. 


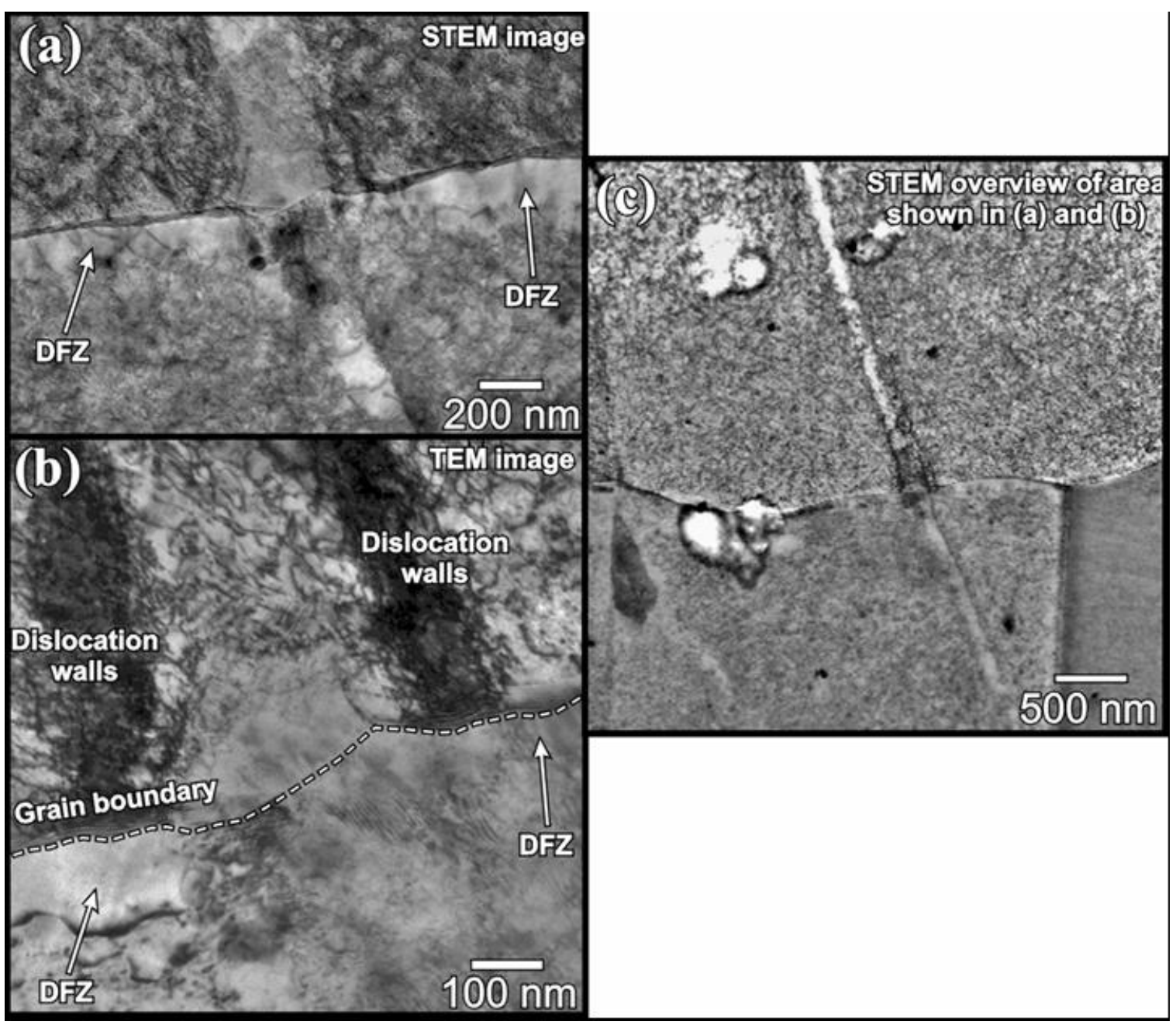

Figure 7. The images in (a) and (b) show two views of the intersection point of a channel with a grain boundary. The overview of the area is provided in (c), showing that another channel formed on the opposite side of the grain boundary. The intersection point exhibits considerable shear of the boundary plane, with the image in (b) highlighting the dense tangles of dislocations that have formed due to this interaction. DFZs are present in the lower grain along the grain boundary as indicated. All of the images were taken in STEM bright field mode from the OFHC-Cu sample irradiated to $0.3 \mathrm{dpa}$ at $323 \mathrm{~K}$ and tested at $323 \mathrm{~K}$ to $1.5 \%$ plastic strain. 


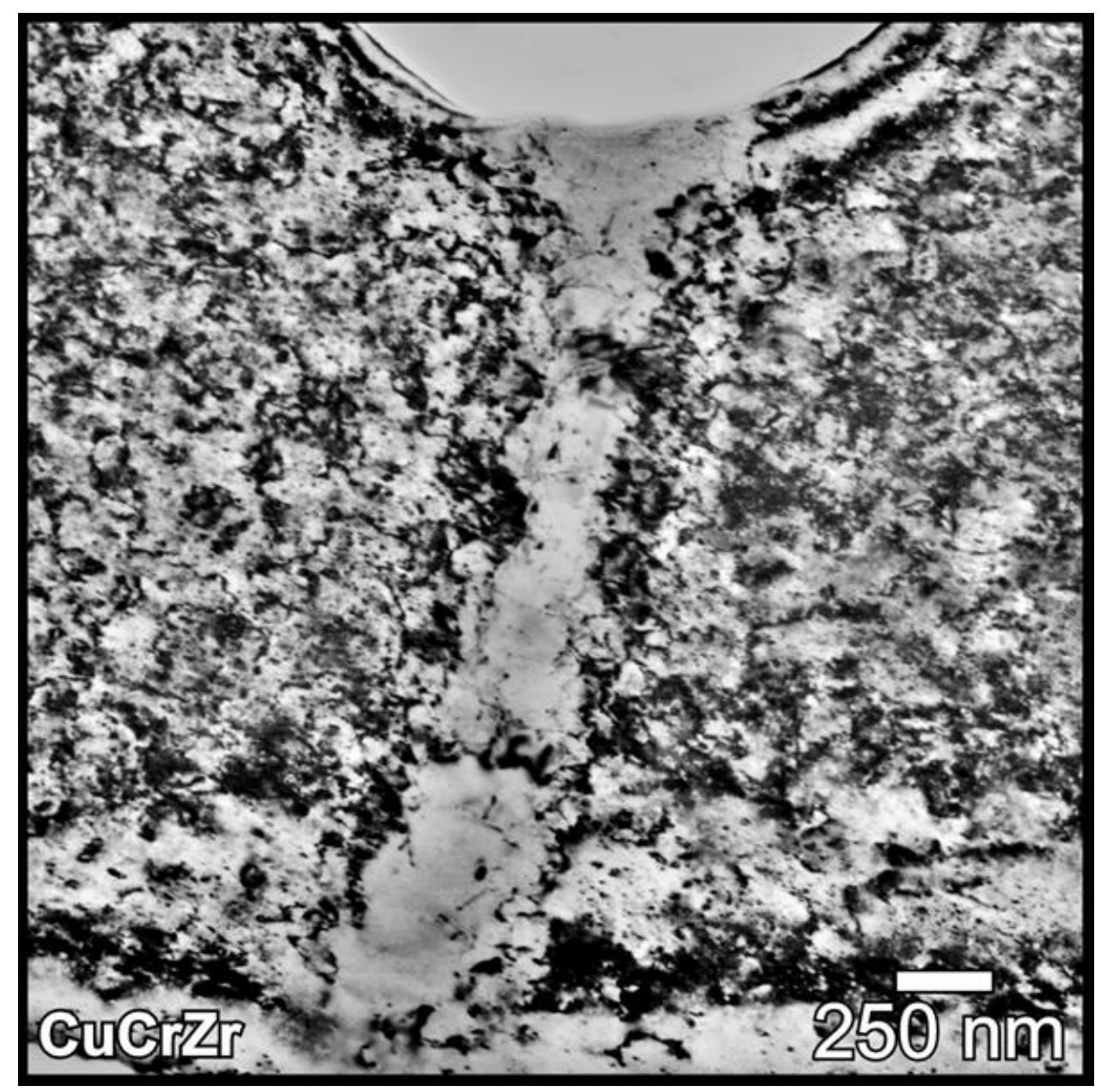

Figure 8. In this example, a channel has been formed in the grain interior from an inclusion that fell out during electropolishing. The $\mathrm{CuCrZr}$ was irradiated to 0.3 dpa at $373 \mathrm{~K}$ and tested at $373 \mathrm{~K}$ to failure. 


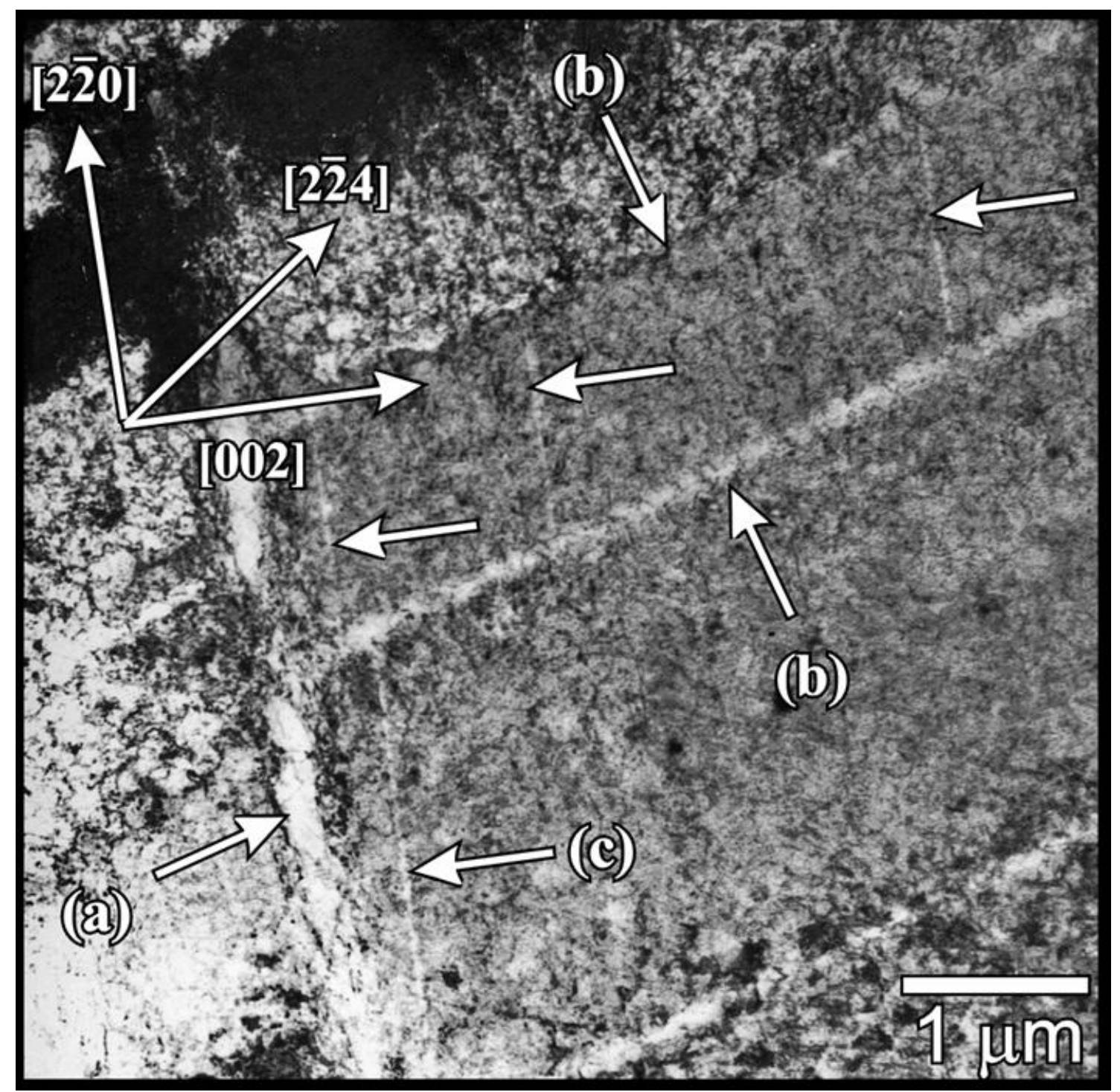

Figure 9. The channels labeled as (a), (b) and (c) correspond to three generations of channels that formed at different stages in OFHC-Cu irradiated to $0.3 \mathrm{dpa}$ at $373 \mathrm{~K}$ and tested to failure at $373 \mathrm{~K}$.. The much narrower channels (labeled as c) link together broader parallel channels formed earlier along the same slip system. The reason for the linking of these broader existing channels by the newer channels is not known. 


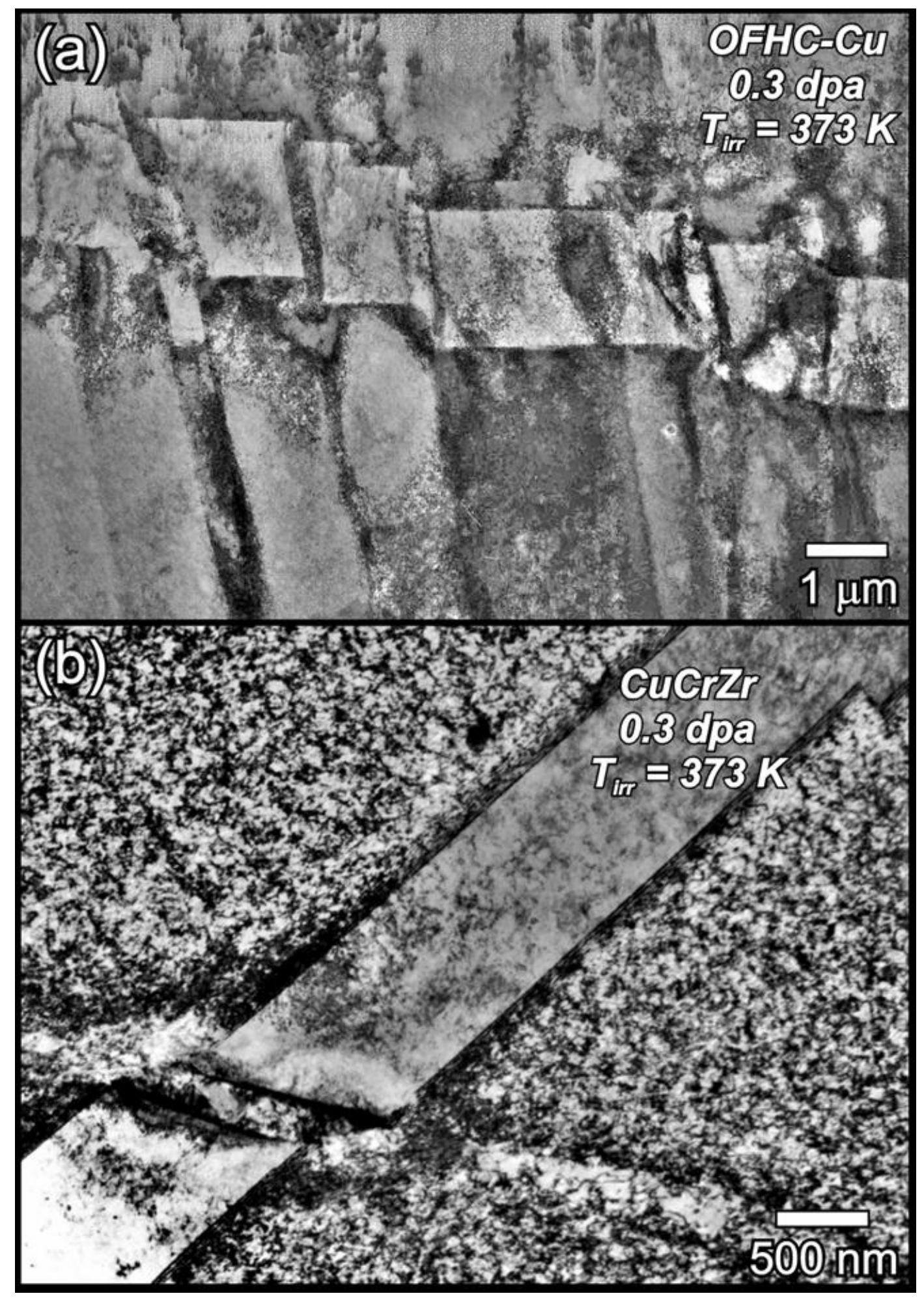

Figure 10. Two examples are shown of annealing twins in (a) OFHC-Cu and in (b) $\mathrm{CuCrZr}$ irradiated at $373 \mathrm{~K}$ to $0.3 \mathrm{dpa}$ that have experienced large degrees of plastic shear from the intersection of channels. The channel intersections with the twin in (a) have produced considerable lattice rotation as well as shear. 


\section{Mission}

To promote an innovative and environmentally sustainable technological development within the areas of energy, industrial technology and bioproduction through research, innovation and advisory services.

\section{Vision}

Risø's research shall extend the boundaries for the understanding of nature's processes and interactions right down to the molecular nanoscale.

The results obtained shall set new trends for the development of sustainable technologies within the fields of energy, industrial technology and biotechnology.

The efforts made shall benefit Danish society and lead to the development of new multi-billion industries. 